\title{
Hematological Parameters and Hemozoin-Containing Leukocytes and Their Association with Disease Severity among Malaria Infected Children: A Cross-Sectional Study at Pawe General Hospital, Northwest Ethiopia
}

\author{
Muluken Birhanu, ${ }^{1}$ Yaregal Asres, ${ }^{2}$ Wondimagegn Adissu, ${ }^{2}$ Tilahun Yemane, \\ Endalew Zemene, ${ }^{2}$ and Lealem Gedefaw ${ }^{2}$ \\ ${ }^{1}$ Department of Medical Laboratory Science, Assosa University, Assosa, Ethiopia \\ ${ }^{2}$ Department of Medical Laboratory Science and Pathology, College of Health Sciences, Jimma University, Jimma, Ethiopia
}

Correspondence should be addressed to Lealem Gedefaw; lealem.gedefaw@ju.edu.et

Received 13 August 2016; Revised 19 January 2017; Accepted 26 January 2017; Published 19 February 2017

Academic Editor: Sandro Cinti

Copyright ( $) 2017$ Muluken Birhanu et al. This is an open access article distributed under the Creative Commons Attribution License, which permits unrestricted use, distribution, and reproduction in any medium, provided the original work is properly cited.

\begin{abstract}
Hematological parameter changes are the most common complications in malaria. We aimed to determine the hematological parameters and hemozoin-containing leukocytes and their association with disease severity in malaria infected children aged between 1 and 15 years. A facility-based cross-sectional study was conducted at Pawe General Hospital from July 31 to December 30, 2014. Demographic and clinical data were collected using structured questionnaire. Blood specimen was collected from each study participant for hematological investigations. Data were analyzed using SPSS version 20 . The overall prevalence of anemia was $40.3 \%$, most of which were mildly anemic. Leukocytosis was found in $15.4 \%$ of study participants. More than a fourth (27\%) of the children had severe malaria. Hemozoin-containing monocytes and neutrophils were found in $80.1 \%$ and $58.9 \%$ of the study participants, respectively. Under-five years of age (AOR $=3.01,95 \%$ CI: $1.83-7.39, P<0.001)$, leukocytosis $(\mathrm{AOR}=3.20,95 \% \mathrm{CI}$ : 1.65-6.24, $P=0.001)$, mean hemozoin-containing monocytes $>5 \%(\mathrm{AOR}=6.26,95 \% \mathrm{CI}: 2.14-14.29, P<0.001)$, mean hemozoincontaining neutrophils $>5 \%$ (AOR $=7.93,95 \% \mathrm{CI}$ : 3.09-16.86, $P<0.001$ ), and high density parasitemia $(\mathrm{AOR}=1.90,95 \% \mathrm{CI}$ : 1.13-3.18, $P=0.015)$ were associated with severe malaria. Hemozoin-containing leukocytes, leukocytosis, and other identified associated factors should be considered for proper management of children with severe malaria.
\end{abstract}

\section{Introduction}

Malaria is one of the infectious diseases that may affect hematological parameters. Anemia, thrombocytopenia, leukocytosis, and leukopenia are the most common hematological complications associated with malaria [1-3]. The extent of these alterations varies with malaria endemicity, background hemoglobinopathy, nutritional status, demographic factors, and malaria immunity [3-5]. Hemozoin (HZ) is the end product of hemoglobin $(\mathrm{Hb})$ digestion by Plasmodia. Both circulating and resident phagocytes acquire HZ through phagocytosis of parasitized red blood cells (PRBCs). Free HZ crystals may also be released after schizont rupture. Some studies show acquisition of HZ by circulating monocytes and neutrophils to be associated with malarial severity $[6,7]$. Detection of HZ pigment within these cells may help in the diagnosis of malaria and is considered as one of the signs of its severity [8-11].

Hematological changes are the most common complications in malaria and play major role in disease outcomes. In malaria endemic areas, severe malarial anemia (SMA) is one of the major factors contributing to anemia resulting in morbidity and mortality among children $[4,5]$. Health facilitybased data show that up to $15 \%$ total deaths among children under five years of age in sub-Saharan Africa (SSA) is attributable to anemia [12]. Malarial anemia is also a major public 
health problem in Ethiopia, with $43.4 \%$ of under-five children with malaria being anemic [13]. Health facility-based studies reported SMA ranging from $13.3 \%$ to $37.8 \%$ among children with SM [14-16]. Moreover, prevalence of mean $\mathrm{HZ}$-containing monocytes (HCMs) and HZ-containing neutrophils (HCNs) ranging from $4 \%$ to $53 \%$ and $2 \%$ to $27 \%$ have been reported among children with SM in Africa, respectively [7, 17-19].

Although there are several factors that increase mortality due to malaria in Ethiopia, the absence of reliable diagnosis and management of SM is the most important. In health facilities in Ethiopia, SM is usually diagnosed by counting the number of asexual parasitaemia in peripheral blood smear of the patients [15]. However, peripheral parasitemia alone is a poor indicator of disease severity, and in many cases the severity of MA does not directly correlate with the number of circulating parasites [20], owing to sequestration within the microvasculature of the host. Some studies reported association of HCMs [10], thrombocytopenia, and leukocytosis [2123] with SM. On the other hand, no association of platelet (PLT) and white blood cell (WBC) counts with malaria severity was found in other studies [24, 25]. The presence and extent of hematological abnormalities in children with malaria and their association with disease severity were not well studied in Ethiopia. Hence, this study was aimed at determining the hematological parameters and HZ-containing leukocytes (HCLs) in children with malaria and their association with disease severity at Pawe General Hospital.

\section{Materials and Methods}

2.1. Study Design and Setting. A facility-based cross-sectional study was conducted at Pawe General Hospital from July 31 to December 30, 2014. Pawe General Hospital is found in Metekel Zone of Benishangul Gumuz Regional State, located $557 \mathrm{kms}$ northwest of Addis Ababa. The hospital serves an estimated 300,000 people in the region, with bed capacity of 180. The geographical coordinates of the area are approximately $11^{\circ} 19^{\prime} \mathrm{N}$ latitude and $36^{\circ} 25^{\prime} \mathrm{E}$ longitude, with altitude range of 1050-1250 meters above sea level. The annual mean rainfall is $1150 \mathrm{~mm}$ with average temperature of $32^{\circ} \mathrm{C}$. The area is characterized by hot and humid climatic condition with stable, year-round transmission of malaria. Even though there is perennial transmission of malaria in the study area, the transmission peaks from September to December, following the main rainy season from June to September $[13,26]$.

2.2. Study Population and Sampling. A total of 377 children diagnosed with malaria by peripheral smear microscopy at the hospital were included in this study. The sample size was estimated using single population proportion formula considering 43\% expected prevalence of malarial anemia [14], 5\% marginal error, and 95\% confidence level. Children of both sexes aged between 1 and 15 years with microscopy-confirmed malaria diagnosed at the outpatient department of the hospital during the study period were included consecutively. Written consent was obtained from parents/guardians before enrollment in the study.
The following exclusion criteria were considered in this study: (1) positivity for intestinal parasite(s) as screened by microscopic examination of wet mount and formolether concentrated stool sample; (2) HIV-1/2-seropositivity as screened by the HIV rapid diagnostic tests (KHB, STAT-PAK, and Uni-Gold); (3) antimalarial treatment 48 hours prior to data collection; (4) history of chronic illness as responded by the parents/guardians of the children.

2.3. Data Collection. Demographic and clinical data of the children were collected by a trained public health officer using structured questionnaire. Moreover, laboratory data including complete blood count (CBC), blood film examination for hemoparasites, and HCLs were generated in this study. Approximately $4 \mathrm{~mL}$ of venous blood was aseptically collected into ethylene diamine tetra acetic acid- (EDTA-) containing vacationer tube. The blood samples were analyzed for $\mathrm{CBC}$ and thin and thick blood smears prepared for microscopic examination of malaria parasites. The CBC was analyzed using CELLDYNE $1800{ }^{\circledR}$ (Abott Laboratories Diagnostics Division, USA) within two hours of sample collection. Thick and thin blood films were prepared on single slide for each study participant. Thin blood smears were methanolfixed before staining. The slides were stained using $10 \%$ Giemsa stain (PH 7.2) for 10 minutes, with the Giemsa stain being prepared immediately before use. The blood smears were examined for malaria parasites, and HCLs were enumerated.

To ensure quality of the data generated in the study, data collectors were trained prior to commencement of the study. Control samples were utilized to ensure accuracy of outputs of the hematology analyzer. Two independent blinded laboratory technologists examined the blood films. In case of discrepancy between the two readings, a third person was involved in reading the slide. Moreover, $10 \%$ of the slides were randomly selected and reexamined by the third laboratory technologist.

2.4. Data Processing and Analysis. Children with at least one of the clinical symptoms: prostration, severe malarial anemia, and hyperparasitemia were classified to have SM [27]. Malaria parasite density was graded as low, moderate, and high, when the parasite count was between $1-999 / \mu \mathrm{L}, 1,000-10,000 / \mu \mathrm{L}$, and $>10,000 / \mu \mathrm{L}$, respectively [28]. Children with $\mathrm{Hb}$ concentration of $5-11 \mathrm{~g} / \mathrm{dL}$ and $<5 \mathrm{~g} / \mathrm{dL}$ were considered to have malarial anemia and severe malarial anemia, respectively [29]. Leukopenia and leukocytosis were considered when the total WBC count was $<4.0 \times 10^{9} / \mathrm{L}$ and $>11.0 \times 10^{9} / \mathrm{L}$, respectively. Thrombocytopenia was defined as PLT count $<150 \times 10^{9} / \mathrm{L}[30]$.

The collected data were checked for completeness regularly during the course of data collection. The data were entered, cleaned, and analyzed using SPSS version 20.0 (SPSS Inc., Chicago, IL). Descriptive statistics including frequency, mean, and standard deviation were utilized to summarize demographic profile of the children and some of the clinical data. Bivariate and multivariable logistic regressions were used to assess association of the independent variables with 
TABLE 1: Demographic and clinical characteristics of the study participants, Pawe General Hospital, 2014.

\begin{tabular}{lccc}
\hline Variables & Categories & Frequency & Percent (\%) \\
\hline \multirow{2}{*}{ Age (years) } & $<5$ & 127 & 33.7 \\
& $\geq 5$ & 250 & 66.3 \\
\hline \multirow{2}{*}{ Sex } & Male & 218 & 57.8 \\
& Female & 159 & 42.2 \\
Axillary temperature & $<37.5^{\circ} \mathrm{C}$ & 151 & 40.1 \\
& $\geq 37.5^{\circ} \mathrm{C}$ & 226 & 59.9 \\
Plasmodium species & P. falciparum & 283 & 75.1 \\
& P. vivax & 57 & 15.1 \\
\hline \multirow{2}{*}{ Malaria severity } & Mixed & 37 & 9.8 \\
& Uncomplicated malaria & 275 & 72.9 \\
\hline
\end{tabular}

${ }^{*}$ Mixed refers to $P$. falciparum and $P$. vivax coinfection.

TABLE 2: Comparison of mean values of hematological parameters and hemozoin-containing leukocytes with malaria severity among the study participants, Pawe General Hospital, 2014.

\begin{tabular}{|c|c|c|c|c|c|}
\hline Parameters & Total mean (SD) & UM & SM & $T$-value ${ }^{*}$ & $P$ value \\
\hline Hb concentration $(\mathrm{g} / \mathrm{dL}), n=377$ & $11.7(2.2)$ & $12.1(1.9)$ & $10.6(2.4)$ & 6.310 & $<0.001$ \\
\hline Hct $(\%), n=377$ & $32.9(5.6)$ & $34.02(4.8)$ & $30.05(6.6)$ & 5.538 & $<0.001$ \\
\hline $\mathrm{RBC}$ count $\left(\times 10^{12} / \mathrm{L}\right), n=377$ & $4.4(0.7)$ & $4.51(0.6)$ & $4.18(0.9)$ & 3.237 & 0.002 \\
\hline WBC count $\left(\times 10^{9} / \mathrm{L}\right), n=377$ & $7.7(3.7)$ & $7.09(3.3)$ & $9.31(4.3)$ & -5.436 & $<0.001$ \\
\hline PLT count $\left(\times 10^{9} / \mathrm{L}\right), n=377$ & $153.0(91.4)$ & $151(80.0)$ & $160(116)$ & -0.735 & 0.464 \\
\hline HCMs (\%), $n=302$ & $9.7(9.2)$ & $7.3(7.2)$ & $16.2(10.9)$ & -7.618 & $<0.001$ \\
\hline HCNs (\%), $n=222$ & $1.7(2.2)$ & $1.25(1.6)$ & $2.8(3.1)$ & -4.685 & $<0.001$ \\
\hline HCMs count $(\operatorname{per} \mu \mathrm{L}), n=302$ & $80.6(34.3)$ & $48.8(46.1)$ & $166.3(82.1)$ & -5.327 & $<0.001$ \\
\hline HCNs count (per $\mu \mathrm{L}), n=222$ & $85.8(37.1)$ & $56.2(69.8)$ & $165.6(80.5)$ & -5.140 & $<0.001$ \\
\hline
\end{tabular}

$\mathrm{Hb}=$ hemoglobin, $\mathrm{Hct}=$ hematocrit, $\mathrm{HCMs}=$ hemozoin-containing monocytes, $\mathrm{HCNs}=$ hemozoin-containing neutrophils, $\mathrm{PLT}=$ platelet, $\mathrm{RBC}=$ red blood cell, $\mathrm{SD}=$ standard deviation, $\mathrm{SM}=$ severe malaria, $\mathrm{UM}=$ uncomplicated malaria, $\mathrm{WBC}=$ white blood cell, and $\mu \mathrm{L}=$ microlitter.

* indicates Student's $t$-test.

the dependent variables. Variables with $P$ value less than 0.25 were candidates for the multivariable logistic regression in this study. $P$ value $<0.05$ was considered significant during the analysis.

2.5. Ethical Considerations. Ethical clearance was obtained from Jimma University Ethical Review Board. Permission was obtained from the Regional Health Bureau. Voluntary participation of the children and their parents/guardians was ensured. Written informed consent was obtained from the parents/guardians of the children before enrollment in the study. Confidentiality of all the clinical information obtained from the children was strictly maintained. All the children who were involved in the study were treated for malaria according to the Malaria Treatment Guidelines [31]. Moreover, children who had intestinal parasitic infection(s) were treated at the hospital.

\section{Results}

3.1. Demographic and Clinical Profiles of the Study Participants. A total of 377 malaria infected children aged 1 to
15 years were included in this study. The mean age of the study participants was $8.5 \pm 4.9$ years. A third of the study participants (33.7\%, $n=127)$ were children between 1 to 5 years. At presentation, 63.9\% $(n=241)$ of the children had fever (axillary temperature $\geq 37.5^{\circ} \mathrm{C}$ ). The majority of malaria cases were due to $P$. falciparum $(75.1 \%, n=283)$ (Table 1$)$.

\subsection{Hematological Parameters and Hemozoin-Containing} Leukocytes. Mean values of the hematological parameters are presented in Table 2. Hemozoin-containing monocytes and HCNs were found in $80.1 \%(n=302)$ and $58.9 \%(n=222)$ of study participants, respectively. On average, 9.7 and $1.7 \%$ of the monocytes and neutrophils contained HZ, respectively. The total HCMs and HCNs per microliter of blood of the study participants were $80.6 \pm 34.3$ and $85.8 \pm 37.1$, respectively. Children with SM had significantly lower mean $\mathrm{Hb}$ concentration, hematocrit value, and RBC count. On the other hand, the children with SM had significantly higher WBC count, mean HCMs count, and HCNs percentages compared to those with uncomplicated malaria. The mean PLT count did not differ significantly between the two groups (Table 2). 
TABLE 3: Factors associated with of severe malaria among the study participants, Pawe General Hospital, 2014.

\begin{tabular}{|c|c|c|c|c|c|c|c|}
\hline Variables & Categories & UM: $N(\%)$ & SM: $N(\%)$ & COR $(95 \% \mathrm{CI})$ & $P$ value & AOR $(95 \% \mathrm{CI})$ & $P$ value \\
\hline \multirow{2}{*}{ Age (year) } & $<5$ & $70(55.1)$ & $57(44.9)$ & $3.71(2.30-5.97)$ & $<0.001$ & $3.01(1.83-7.39)$ & $<0.001$ \\
\hline & $\geq 5$ & $205(82.0)$ & $45(18.0)$ & 1 (ref) & & 1 (ref) & \\
\hline \multirow{2}{*}{ Sex } & Male & $160(73.4)$ & $58(26.6)$ & $1.05(0.67-1.67)$ & 0.818 & & \\
\hline & Female & $115(72.3)$ & $44(27.7)$ & 1 (ref) & & & \\
\hline \multirow{2}{*}{ Axillary temperature $\left({ }^{\circ} \mathrm{c}\right)$} & $<37.5$ & $113(74.8)$ & $38(25.2)$ & 1 (ref) & & & \\
\hline & $37.5-39.4$ & $162(71.7)$ & $64(28.3)$ & $1.24(0.76-2.04)$ & 0.235 & $1.03(0.57-1.84)$ & 0.960 \\
\hline \multirow{2}{*}{ Anemia } & Yes & $93(61.2)$ & $59(38.8)$ & $2.68(1.69-4.28)$ & $<0.001$ & $1.65(0.93-2.92)$ & 0.089 \\
\hline & No & $182(80.9)$ & $43(19.1)$ & 1 (ref) & & 1 (ref) & \\
\hline \multirow{2}{*}{ Leukocytosis } & Yes & $32(55.2)$ & $26(44.8)$ & $2.6(1.46-4.63)$ & $<0.001$ & $3.20(1.65-6.24)$ & 0.001 \\
\hline & No & $243(76.2)$ & $76(23.8)$ & 1 (ref) & & 1 (ref) & \\
\hline \multirow{2}{*}{ Leukopenia } & Yes & $33(84.6)$ & $6(15.4)$ & $0.46(0.19-1.13)$ & 0.090 & $0.68(0.25-1.88)$ & 0.462 \\
\hline & No & $242(71.6)$ & $96(28.4)$ & 1 (ref) & & 1 (ref) & \\
\hline \multirow{2}{*}{ Thrombocytopenia } & Yes & $154(72.0)$ & $60(28.0)$ & $1.12(0.71-1.78)$ & 0.623 & & \\
\hline & No & $121(74.2)$ & $42(25.8)$ & 1 (ref) & & & \\
\hline \multirow{3}{*}{ HCMs } & No HCMs & $70(93.3)$ & $5(6.7)$ & 1 (ref) & & 1 (ref) & \\
\hline & $0.5-5 \%$ & $143(77.7)$ & $41(22.3)$ & $2.04(0.63-6.57)$ & 0.234 & $3.77(1.39-10.20)$ & 0.009 \\
\hline & $>5 \%$ & $62(52.5)$ & $56(47.5)$ & $8.31(3.23-1.36)$ & $<0.001$ & $6.26(2.14-14.29)$ & $<0.001$ \\
\hline \multirow{3}{*}{$\mathrm{HCNs}$} & No HCNs & $125(80.6)$ & $30(29.4)$ & 1 (ref) & & 1 (ref) & \\
\hline & $0.5-5 \%$ & $143(73.7)$ & $51(26.3)$ & $1.49(0.89-2.48)$ & 0.129 & $0.79(0.43-1.46)$ & 0.455 \\
\hline & $>5 \%$ & $7(25)$ & $21(75)$ & $12.5(4.86-2.12)$ & $<0.001$ & $7.93(3.09-16.86)$ & $<0.001$ \\
\hline \multirow{3}{*}{ Plasmodium species } & P. falciparum & $191(67.5)$ & $92(32.5)$ & $5.56(1.63-11.12)$ & 0.006 & & \\
\hline & P. vivax & $50(87.7)$ & $7(12.3)$ & $1.59(0.38-6.57)$ & 0.524 & & \\
\hline & Mixed* & 34 (91.9) & $3(8.1)$ & 1 (ref) & & & \\
\hline \multirow{2}{*}{ High parasitemia } & Yes & $117(65.0)$ & $63(35.0)$ & $2.18(1.37-3.47)$ & 0.001 & $1.90(1.13-3.18)$ & 0.015 \\
\hline & No & $158(80.2)$ & $39(19.8)$ & 1 (ref) & & 1 (ref) & \\
\hline
\end{tabular}

$\mathrm{UM}=$ uncomplicated malaria, $\mathrm{SM}=$ severe malaria, $N=$ number, $\mathrm{COR}=$ crude odds ratio, $\mathrm{AOR}=$ adjusted odds ratio, $\mathrm{CI}=$ confidence interval, $\mathrm{HCMs}=$ hemozoin containing monocytes, HCNs $=$ hemozoin containing neutrophils, ref $=$ reference, and $\mu \mathrm{L}=$ microliter. ${ }^{*}$ Mixed refers to $P$. falciparum and $P$. vivax coinfection.

3.3. Factors Associated with Severe Malaria. Factors associated with severe malaria among the children are demonstrated in Table 3. Out of the total study participants, $40.3 \%$ $(n=152)$ were anemic, of whom $87.5 \%$ ( $n=133), 9.2 \%$ $(n=14)$, and $3.3 \%(n=5)$ had mild, moderate, and severe anemia, respectively. Thrombocytopenia was found in $56.8 \%$ ( $n=214)$ of the study participants. Mild, moderate, and severe thrombocytopenia accounted for $41.6 \%(n=89)$, $45.3 \%(n=97)$ and $13.1 \%(n=28)$ of the children with thrombocytopenia, respectively. Leukocytosis and leukopenia were found in $15.4 \%(n=58)$ and $10.3 \%(n=39)$ of the study participants, respectively.

After adjusting for all the measured explanatory variables in the multivariable regression model, under-five years of age $(\mathrm{AOR}=3.01,95 \% \mathrm{CI}: 1.83-7.39)$, leukocytosis $(\mathrm{AOR}=3.20$, 95\% CI: $1.65-6.24)$, mean HCMs >5\% (AOR = 6.26, 95\% CI: 2.14-14.29), mean HCNs >5\% (AOR = 7.93, 95\% CI: 3.09$16.86)$, and high parasitemia ( $\mathrm{AOR}=1.90,95 \% \mathrm{CI}: 1.13-3.18)$ were associated with SM.

\section{Discussion}

The main aim of this study was to determine the common hematological indices and HCLs among the malaria infected children. Accordingly, the overall prevalence of anemia was $40.3 \%$. Anemia is a common complication associated with malaria $[4,14,30,32]$, specially associated with falciparum malaria. The magnitude of anemia among malaria infected patients varies depending on demographic factors, nutritional status, preexisting physiologic conditions, and coinfection with other diseases $[33,34]$. It is revealed in this study that the mean $\mathrm{Hb}$ concentration was significantly lower in children with SM compared to children with UM. The causes and mechanisms of anemia in malaria are diverse, which may include RBC destruction and effect on erythroid development $[35,36]$. The high prevalence of anemia among the children requires urgent attention to curb its long-term impacts.

In this study, nearly half of the children had moderate to mild thrombocytopenia. Low PLT associated with malaria in malaria endemic areas has also been reported previously [4, 37-41]. The exact mechanism of pathogenesis of malarial thrombocytopenia is not clear. Suggested mechanisms of thrombocytopenia in malaria include splenic phagocytosis of activated platelets, coagulation disturbances, and bone marrow alterations $[42,43]$. Unless treated early, thrombocytopenia may also play role in the pathogenesis of cerebral malaria [3]. 
Leukocytosis and leukopenia were found in $15.4 \%$ and $10.3 \%$ of the study participants, respectively. Moreover, children who had leukocytosis were 3 times more likely to have SM. Other studies also show significant association of leukocytosis with SM [22, 23, 37]. Leukocytes, particularly the monocytes and to a lesser extent neutrophils, play crucial role in the host defense against malaria parasites. As the severity of the disease progress, there might be overstimulation of the leukocytes resulting in imbalanced and excessive production of inflammatory cytokines, which may further contribute to the severity of the disease $[44,45]$.

In this study, it was also revealed that most of the malaria infected children had HCMs and HCNs in their peripheral blood smear. The interaction of $\mathrm{HZ}$ with immune cells may result in upregulation or downregulation of immune mediators [46-48] affecting host innate and inflammatory immune responses. Hemozoin may also be involved in the inhibition of erythropoiesis in malarial anemia $[49,50]$, likely by stimulation of apoptosis of erythroid precursors [51]. The high proportion of children with HCLs in this study requires vigilance over the course of the disease in this area, as HCLs could be associated with SM [9]. Evaluation of duration of persistence of $\mathrm{HZ}$ within the mononuclear cells and polymorphs following parasite clearance was not within the scope of this study. A previous study reported persistence of $\mathrm{HZ}$ in spleen and liver in mouse models, after parasite clearance [52].

The findings of this study should be interpreted in light of the following limitations. As no locally established reference range for hematological parameters in children was obtained, the WHO reference range was utilized. Although certain bacterial infections can profoundly perturb hematological parameters, thereby affecting their diagnostic value in determining severity of malaria, this study did not investigate any bacterial coinfections.

\section{Conclusion}

Over a quarter of the children with malaria had SM. Demographic and hematological parameters significantly affected the malaria disease outcome among the studied children. The presence and quantities of HCLs and other hematological parameters should be considered in the management of children with malaria in the study area. Further longitudinal studies with larger sample size are needed to determine the association of hematological parameters with SMA.

\section{Competing Interests}

The authors declare that they do not have competing interests.

\section{Acknowledgments}

The authors would like to thank the data collectors for participating in the data collection and Pawe General Hospital for allowing them to use the laboratory facilities of the hospital. The authors are grateful to the study participants and their parents/guardians. The authors thank Jimma University for financially supporting this study.

\section{References}

[1] O. Erhabor, H. J. Mohammad, H. M. Ahmed, and A. C. Ezimah, "Effect of plasmodium parasitaemia on some haematological parameters in children living in Sokoto, North Western, Nigeria," International Journal of Clinical Medicine Research, vol. 1, no. 2, pp. 57-64, 2014.

[2] C. Casals-Pascual, O. Kai, C. R. J. C. Newton, N. Peshu, and D. J. Roberts, "Short report: thrombocytopenia in falciparum malaria is associated with high concentrations of IL-10," American Journal of Tropical Medicine and Hygiene, vol. 75, no. 3, pp. 434-436, 2006.

[3] D. Cox and S. McConkey, "The role of platelets in the pathogenesis of cerebral malaria," Cellular and Molecular Life Sciences, vol. 67, no. 4, pp. 557-568, 2010.

[4] R. N. Maina, D. Walsh, C. Gaddy et al., "Impact of Plasmodium falciparum infection on haematological parameters in children living in Western Kenya," Malaria Journal, vol. 9, no. 3, article S4, 2010.

[5] M. Imoru, U. A. Shehu, U. G. Ihesiulor, and A. H. Kwaru, "Haematological changes in malaria-infected children in NorthWest Nigeria," Turkish Journal of Medical Sciences, vol. 43, no. 5, pp. 838-842, 2013.

[6] G. A. Awandare, Y. Ouma, C. Ouma et al., "Role of monocyteacquired hemozoin in suppression of macrophage migration inhibitory factor in children with severe malarial anemia," Infection and Immunity, vol. 75, no. 1, pp. 201-210, 2007.

[7] O. K. Amodu, A. A. Adeyemo, P. E. Olumese, and R. A. Gbadegesin, "Intraleucocytic malaria pigment and clinical severity of malaria in children," Transactions of the Royal Society of Tropical Medicine and Hygiene, vol. 92, no. 1, pp. 54-56, 1998.

[8] M. P. Grobusch, T. Hänscheid, B. Krämer et al., "Sensitivity of hemozoin detection by automated flow cytometry in nonand semi-immune malaria patients," Cytometry Part B - Clinical Cytometry, vol. 55, no. 1, pp. 46-51, 2003.

[9] Y. Kodandapani, P. Srinivas, P. Ramya, and K. Venu, "Association of leucocytosis and hemozoin pigment in leucocytes with disease severity of malaria in children," IOSR Journal of Dental and Medical Sciences, vol. 14, no. 11, pp. 44-51, 2015.

[10] C. P. Ihekwereme, C. O. Esimone, and E. C. Nwanegbo, "Hemozoin inhibition and control of clinical malaria," Advances in Pharmacological Sciences, vol. 2014, Article ID 984150, 7 pages, 2014.

[11] G. Mujuzi, B. Magambo, B. Okech, and T. G. Egwang, "Pigmented monocytes are negative correlates of protection against severe and complicated malaria in Ugandan children," American Journal of Tropical Medicine and Hygiene, vol. 74, no. 5, pp. 724-729, 2006.

[12] B. J. Brabin, Z. Premji, and F. Verhoeff, "An analysis of anemia and child mortality," Journal of Nutrition, vol. 131, no. 2, supplement 2, pp. 636S-648S, 2001.

[13] The Ethiopian Health and Nutrition Research Institute and Partners, Ethiopia National Malaria Indicator Survey 2011, 2012.

[14] T. Ketema and K. Bacha, "Plasmodium vivax associated severe malaria complications among children in some malaria endemic areas of Ethiopia," BMC Public Health, vol. 13, no. 1, article no. 637, 2013.

[15] Z. Tekeste, M. Workineh, and B. Petros, "Determining the severity of Plasmodium falciparum malaria in Ethiopia," Journal of Infection and Public Health, vol. 6, no. 1, pp. 10-15, 2013.

[16] B. Gebre and Y. Negash, "Severe malaria among children in Gambella, western Ethiopia," Ethiopian Journal of Health Development, vol. 16, no. 1, pp. 61-70, 2002. 
[17] P. G. Kremsner, C. Valim, M. A. Missinou et al., "Prognostic value of circulating pigmented cells in African children with malaria," The Journal of Infectious Diseases, vol. 199, no. 1, pp. 142-150, 2009.

[18] T. Hänscheid, M. Längin, B. Lell et al., "Full blood count and haemozoin-containing leukocytes in children with malaria: diagnostic value and association with disease severity," Malaria Journal, vol. 7, article no. 109, 2008.

[19] K. E. Lyke, D. A. Diallo, A. Dicko et al., "Association of intraleukocytic Plasmodium falciparum malaria pigment with disease severity, clinical manifestations, and prognosis in severe malaria," The American Journal of Tropical Medicine and Hygiene, vol. 69, no. 3, pp. 253-259, 2003.

[20] J. P. Quintero, A. M. Siqueira, A. Tobón et al., "Malaria-related anaemia: a Latin American perspective," Memorias do Instituto Oswaldo Cruz, vol. 106, no. 1, pp. 91-104, 2011.

[21] P. Gérardin, C. Rogier, A. S. Ka, P. Jouvencel, V. Brousse, and P. Imbert, "Prognostic value of thrombocytopenia in African children with falciparum malaria," The American Journal of Tropical Medicine and Hygiene, vol. 66, no. 6, pp. 686-691, 2002.

[22] C. M. Cserti-Gazdewich, A. Dhabangi, C. Musoke et al., "Interrelationships of cardinal features and outcomes of symptomatic pediatric Plasmodium falciparum malaria in 1,933 children in Kampala, Uganda," The American Journal of Tropical Medicine and Hygiene, vol. 88, no. 4, pp. 747-756, 2013.

[23] D. Modiano, B. S. Sirima, A. Konaté, I. Sanou, and A. Sawadogo, "Leucocytosis in severe malaria," Transactions of the Royal Society of Tropical Medicine and Hygiene, vol. 95, no. 2, pp. 175176, 2001.

[24] P. S. Boeuf, S. Loizon, G. A. Awandare et al., "Insights into deregulated TNF and IL-10 production in malaria: implications for understanding severe malarial anaemia," Malaria Journal, vol. 11, article 253, 2012.

[25] A. Mayor, A. Hafiz, Q. Bassat et al., "Association of severe malaria outcomes with platelet-mediated clumping and adhesion to a novel host receptor," PLoS ONE, vol. 6, no. 4, Article ID e19422, 2011.

[26] President's Malaria Initiative Ethiopia, Malaria Operational Plan FY, 2014.

[27] World Health Organization, Guidelines for the Treatment of Malaria, 2nd edition, 2010.

[28] M. Cheesbrough, District Laboratory Practice in Tropical Countries, Cambridge University Press, 2nd edition, 2005.

[29] World Health Organization, "Communicable diseases cluster, 'Severe falciparum malaria,' Transactions of the Royal Society of Tropical Medicine and Hygiene, vol. 94, supplement 1, pp. S1S90, 2000.

[30] A. D. Adedapo, C. O. Falade, R. T. Kotila, and G. O. Ademowo, "Age as a risk factor for thrombocytopenia and anaemia in children treated for acute uncomplicated falciparum malaria," Journal of Vector Borne Diseases, vol. 44, no. 4, pp. 266-271, 2007.

[31] A. Olutola and O. Mokuolu, "Severe Malaria anaemia in children," in Anemia, D. S. Silverberg, Ed., chapter 18, InTech, Rijeka, Croatia, 2012, http://www.intechopen.com/books/anemia/severe-malaria-anaemia-in-children

[32] C. Piccolo, M. Vargas, E. Sanchez, A. Rodriguez-Morales, R. Colina, and M. Arria, "Anemia and thrombocytopenia in children with P. vivax malaria," Journal of Tropical Pediatrics, vol. 52, no. 1, pp. 49-51, 2006.

[33] S. Brooker, W. Akhwale, R. Pullan et al., "Epidemiology of Plasmodium-helminth co-infection in Africa: populations at risk, potential impact on anemia, and prospects for combining control," American Journal of Tropical Medicine and Hygiene, vol. 77, supplement 6, pp. 88-98, 2007.

[34] B.-T. Huynh, N. Fievet, G. Gbaguidi et al., "Influence of the timing of malaria infection during pregnancy on birth weight and on maternal anemia in Benin," American Journal of Tropical Medicine and Hygiene, vol. 85, no. 2, pp. 214-220, 2011.

[35] P. A. Buffet, I. Safeukui, G. Deplaine et al., "The pathogenesis of Plasmodium falciparum malaria in humans: insights from splenic physiology," Blood, vol. 117, no. 2, pp. 381-392, 2011.

[36] T. Panichakul, W. Payuhakrit, P. Panburana, C. Wongborisuth, S. Hongeng, and R. Udomsangpetch, "Suppression of erythroid development in vitro by Plasmodium vivax," Malaria Journal, vol. 11, article 173, 2012.

[37] S. Ladhani, B. Lowe, A. O. Cole, K. Kowuondo, and C. R. J. C. Newton, "Changes in white blood cells and platelets in children with Falciparum malaria: relationship to disease outcome," British Journal of Haematology, vol. 119, no. 3, pp. 839-847, 2002.

[38] F. Moulin, F. Lesage, A.-H. Legros et al., "Thrombocytopenia and Plasmodium falciparum malaria in children with different exposures," Archives of Disease in Childhood, vol. 88, no. 6, pp. 540-541, 2003.

[39] E. E. Utuk, E. E. Ikpeme, I. J. Emodi, and E. M. Essien, "The prevalence of thrombocytopenia in Plasmodium falciparum malaria in children at the University of Uyo Teaching Hospital, Uyo, Nigeria," Nigerian Journal of Paediatrics, vol. 41, no. 1, pp. 28-32, 2014.

[40] N. Latif, M. S. Ejaz, S. Hanif, and H. Memon, "Clinical and hematological pattern in patients with Plasmodium vivax," Medical Channel, vol. 18, no. 1, pp. 48-51, 2012.

[41] G. Shetty, K. S. Avabratha, S. Gonsalves, A. Dany, and B. S. Rai, "Thrombocytopenia in children with malaria-a study from coastal Karnataka, India," Asian Pacific Journal of Tropical Disease, vol. 2, no. 2, pp. 107-109, 2012.

[42] H. C. C. Coelho, S. C. P. Lopes, J. P. D. Pimentel et al., "Thrombocytopenia in Plasmodium vivax malaria is related to platelets phagocytosis," PLoS ONE, vol. 8, no. 5, Article ID e63410, 2013.

[43] M. V. G. Lacerda, M. P. G. Mourão, H. C. Coelho, and J. B. Santos, "Thrombocytopenia in malaria: who cares?" Memorias do Instituto Oswaldo Cruz, vol. 106, supplement 1, pp. 52-63, 2011.

[44] E. Y. Denkers and R. T. Gazzinelli, "Effector functions of macrophages in Plasmodium parasite infections," in Protozoans in Macrophages, pp. 160-172, Landes Bioscience, Austin, Tex, USA, 2007.

[45] M. Olivier, K. Van Den Ham, M. T. Shio, F. A. Kassa, and S. Fougeray, "Malarial pigment hemozoin and the innate inflammatory response," Frontiers in Immunology, vol. 5, 2014.

[46] M. T. Shio, S. C. Eisenbarth, M. Savaria et al., "Malarial hemozoin activates the NLRP3 inflammasome through Lyn and Syk kinases," PLoS pathogens, vol. 5, no. 8, Article ID e1000559, 2009.

[47] R. Ranjan and M. Karpurapu, "Hemozoin regulates iNOS expression by modulating the transcription factor NF-kB in macrophages," Biochemistry \& Molecular Biology Journal, vol. 2, no. 2, 2016.

[48] C. Coban, Y. Igari, M. Yagi et al., "Immunogenicity of wholeparasite vaccines against Plasmodium falciparum involves malarial hemozoin and host TLR9," Cell Host and Microbe, vol. 7, no. 1, pp. 50-61, 2010.

[49] O. A. Skorokhod, L. Caione, T. Marrocco et al., "Inhibition of erythropoiesis in malaria anemia: role of hemozoin and 
hemozoin-generated 4-hydroxynonenal," Blood, vol. 116, no. 20, pp. 4328-4337, 2010.

[50] C. Casals-Pascual, O. Kai, J. O. P. Cheung et al., "Suppression of erythropoiesis in malarial anemia is associated with hemozoin in vitro and in vivo," Blood, vol. 108, no. 8, pp. 2569-2577, 2006.

[51] A. A. Lamikanra, M. Theron, T. W. A. Kooij, and D. J. Roberts, "Hemozoin (Malarial pigment) directly promotes apoptosis of erythroid precursors," PLoS ONE, vol. 4, no. 12, 2009.

[52] M. A. Levesque, A. D. Sullivan, and S. R. Meshnick, "Splenic and hepatic hemozoin in mice after malaria parasite clearance," Journal of Parasitology, vol. 85, no. 3, pp. 570-573, 1999. 


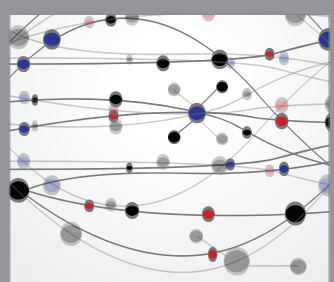

The Scientific World Journal
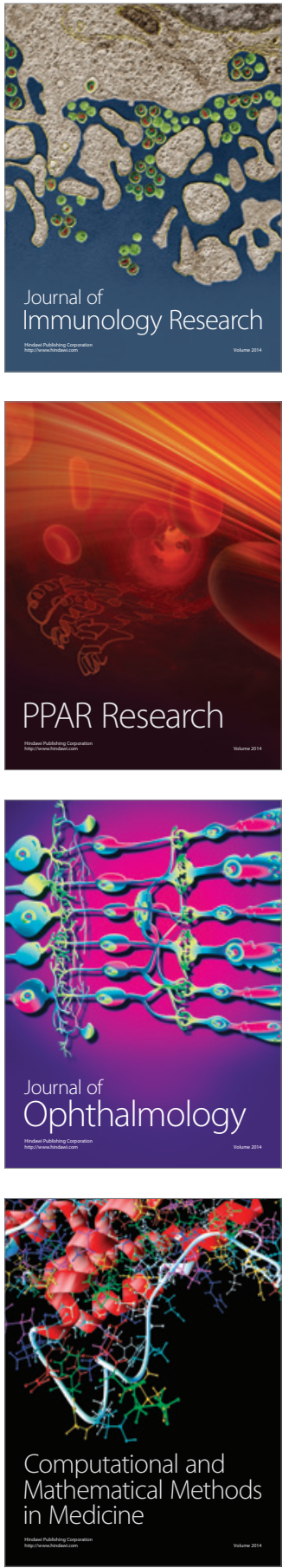

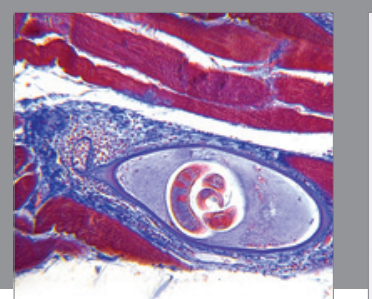

Gastroenterology Research and Practice
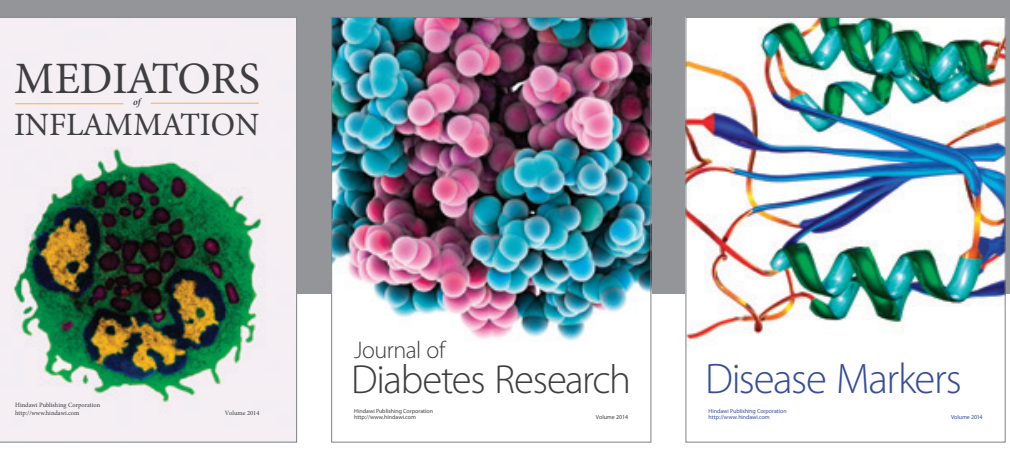

Disease Markers

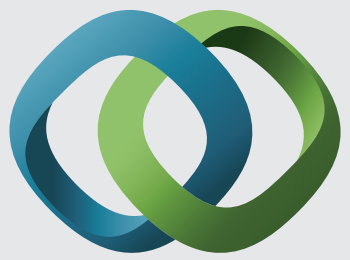

\section{Hindawi}

Submit your manuscripts at

https://www.hindawi.com
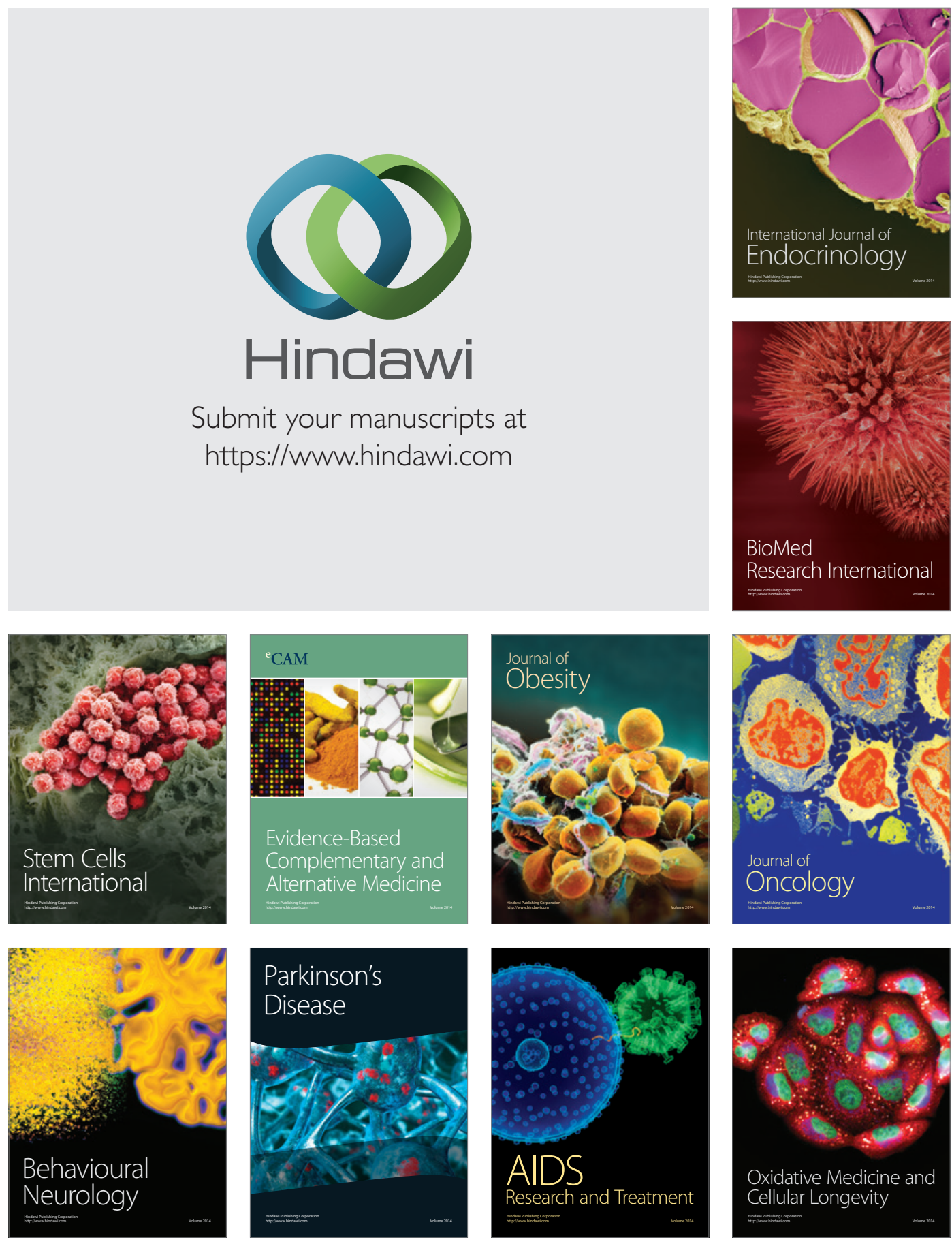